\title{
Neoadjuvant Platinum-Based Chemotherapy is an Independent Predictor for Preoperative Thromboembolic Events in Bladder Cancer Patients Undergoing Radical Cystectomy
}

\author{
Cliodhna Browne Niall F. Davis William J. Nolan Eoin D. MacCraith \\ Gerald M. Lennon David W. Mulvin David J. Galvin David M. Quinlan
}

Department of Urology, St. Vincent's University Hospital, Dublin, Ireland

\section{Key Words}

Neoadjuvant chemotherapy • Radical cystectomy •

Muscle-invasive bladder cancer $•$ Venous thromboembolism

\begin{abstract}
Introduction: Neoadjuvant chemotherapy (NAC) confers a significant survival benefit in patients with muscle invasive bladder cancer. Platinum-based chemotherapy increases the risk of thromboembolic events (TEE). We determined the effect of cisplatin-based NAC on the incidence of preoperative TEEs in radical cystectomy patients. Materials and Methods: A retrospective matched case-control study was performed on 55 patients undergoing radical cystectomy for muscle invasive bladder cancer. Group $1(n=20)$ included patients that received NAC prior to radical cystectomy and Group $2(n=35)$ included patients that underwent radical cystectomy without NAC. Logistic regression analyses tested potential predictors for TEEs in both groups (age, American Society of Anesthesiologists grade, use of NAC, histological subtype, pathological stage). Results: In total, 6 patients of 55 developed a TEE. Five patients of $20(25 \%)$ treated with NAC prior to radical cystectomy developed TEEs, while 1 of $35(2.9 \%)$ treated with radical cystectomy alone developed a
\end{abstract}

\section{KARGER}

(C) 2016 S. Karger AG, Basel

Fax +4161306 1234

E-Mail karger@karger.ch

www.karger.com

Accessible online at:

www.karger.com/cur
TEE. On univariate and multivariate regression analysis, NAC prior to radical cystectomy was an independent predictor for TEE prior to radical cystectomy $(p=0.033$ and $p=0.043$, respectively). The effect of perioperative anticoagulation on operative blood loss and postoperative hemoglobin level was not statistically significant between both groups ( $p=$ 0.22 and $p=0.08$, respectively). Conclusion: Neoadjuvant cisplatin-based chemotherapy is a significant predictor for preoperative TEE in patients undergoing radical cystectomy.

Copyright $\odot 2016$ S. Karger AG, Basel

\section{Introduction}

Malignancy induces a hypercoagulable state and increases the risk of thromboembolic events (TEEs). Cisplatin-based neoadjuvant chemotherapy (NAC) followed by radical cystectomy is the standard of care for suitable patients with muscle-invasive bladder cancer as it confers a significant survival benefit in patients with locally advanced bladder cancer compared with radical cystectomy alone $[1,2]$. A potential disadvantage of plat- 
Table 1. Demographics, operative outcomes and stage of disease on histopathology after radical cystectomy

\begin{tabular}{llll}
\hline & Group 1 $(\mathrm{n}=20)$ & Group 2 $(\mathrm{n}=35) \mathrm{p}$ \\
\hline $\begin{array}{l}\text { Median age, years } \\
\text { Median ASA grade }\end{array}$ & 64 & 68 & 0.46 \\
(range) & $2(2-3)$ & $2(1-3)$ & 0.9 \\
$\begin{array}{l}\text { Gender } \\
\quad \text { Female }\end{array}$ & $20 \%$ & $34 \%$ & - \\
$\quad$ Male & $80 \%$ & $66 \%$ & \\
Blood loss, ml & $1,980 \pm 986$ & $1,655 \pm 918$ & 0.22 \\
Hemoglobin drop, g/dl & $2.74 \pm 1.7$ & $2.15 \pm 2.25$ & 0.08 \\
Pathological stage & & & \\
(patients No.) & & & - \\
$\quad$ pT0 & 9 & 3 & - \\
pTis & 2 & 1 & - \\
pTa & 0 & 1 & - \\
pT1 & 0 & 6 & - \\
pT2 & 2 & 10 & - \\
pT3 & 3 & 12 & - \\
pT4 & 4 & 2 & - \\
Node status & & & - \\
(patients No.) & & 9 & - \\
NX & 5 & 3 & \\
N0 & 11 & 3 & \\
N1 & 1 & & \\
N2 & 3 & & \\
\hline
\end{tabular}

ASA = American Society of Anesthesiologists.

inum-based chemotherapy in the perioperative setting is an increased risk of perioperative TEEs [3-5]. The aim of this retrospective analysis was to investigate the effect of cisplatin-based NAC on the incidence of preoperative TEEs in patients undergoing radical cystectomy. We also assessed the effect of therapeutic anticoagulation on operative blood loss.

\section{Materials and Methods}

\section{Overview of Study Design}

Approval for the study was granted by the ethics board of St. Vincent's University Hospital, Dublin, Ireland. Patients undergoing radical cystectomy for muscle invasive bladder cancer were identified from a prospectively maintained operative database from 2005 to 2015. A retrospective matched case-control study was conducted and patients were divided into 2 groups. Group 1 $(n=20)$ consisted of patients that received neoadjuvant cisplatin-based chemotherapy prior to radical cystectomy. Group $2(\mathrm{n}=$ 35) consisted of patients that underwent radical cystectomy without NAC. Patients were matched for age at surgery and American Society of Anesthesiologists (ASA) grade. No patients in either group had a prior history of venous thromboembolic disease.

\section{Predictors for Thromboembolic Events}

We used logistic regression analyses to test potential predictors for preoperative TEEs in both groups. TEEs were defined as pulmonary emboli or deep vein thrombosis occurring in the time from diagnosis of bladder cancer to the date of surgery. Potential predictors were age, ASA grade, use of NAC, histological subtype and pathological stage. Logistic regression analysis was performed with the occurrence of a TEE treated as the dependent variable and NAC as the primary independent variable. Further logistic regression analysis was performed to assess if age and/ or ASA grade influenced the rate of thromboembolic events. The effect of therapeutic anticoagulation used in patients who developed TEEs on operative blood loss was also assessed by performing logistic regression analysis using anticoagulation status and decrease in hemoglobin level as independent variables. Student's t-tests with unequal variances were performed for pairwise comparisons.

\section{Results}

\section{Patient Demographics}

Fifty-five patients undergoing radical cystectomy for locally advanced bladder cancer were included in the analysis. Twenty patients (36.4\%) received NAC prior to radical cystectomy and 35 patients $(63.6 \%)$ were treated with radical cystectomy alone. The median age was 64 years in Group 1 (range 44-77 years) and 68 years in Group 2 (range 39-79 years) $(\mathrm{p}=0.46)$. The median ASA grade in both groups was 2. Patient demographics and final pathological staging from radical cystectomy specimen are outlined in table 1.

\section{Incidence and Treatment of TEEs}

Among the 20 patients who received NAC, 5 patients had a preoperative TEE (25\%) compared to 1 of the 35 patients $(3 \%)$ who proceeded directly to radical cystectomy. All patients diagnosed with preoperative TEE were treated with perioperative therapeutic heparin anticoagulation. Two patients underwent insertion of a caval filter preoperatively. All patients without venous thromboembolism (VTE) were treated with prophylactic low molecular weight heparin (LMWH) in the perioperative period. Three patients in Group 1 had pulmonary embolism and 2 patients had deep venous thrombosis (DVT) of the lower limb. All pulmonary emboli were asymptomatic and were diagnosed on routine preoperative CT of the thorax, abdomen and pelvis. All DVTs presented with symptoms and were diagnosed on Doppler ultrasonography of the affected lower limb. One patient in Group 2 was diagnosed with asymptomatic pulmonary embolism on routine preoperative $\mathrm{CT}$ abdomen and pelvis. Both univariate and multivariate analysis indicated that NAC 
prior to radical cystectomy was an independent predictor for preoperative TEEs $(p=0.033$ and $p=0.043$, respectively).

\section{Therapeutic Anticoagulation and Operative Blood \\ Loss}

Mean operative blood loss was 1,980 $\pm 986 \mathrm{ml}$ in Group 1 and 1,655 $\pm 918 \mathrm{ml}$ in Group $2(\mathrm{p}=0.22)$. The mean decrease in hemoglobin on the first postoperative day was $2.74 \pm 1.7 \mathrm{~g} / \mathrm{dl}$ in Group 1 and $2.15 \pm 2.25 \mathrm{~g} / \mathrm{dl}$ in Group 2. The effect of perioperative anticoagulation on postoperative hemoglobin level was not significant in this sample size $(\mathrm{p}=0.08)$.

\section{Discussion}

Predisposition to perioperative VTE in major pelvic surgery for malignant disease is well established. In patients undergoing radical cystectomy length of hospital stay, increased blood loss, body mass index, surgical margins, type of urinary diversion and prior history of DVT have been identified as risk factors for developing VTE [6-8]. Therefore extended perioperative thromboprophylaxis is frequently recommended [9]. Notably, data on NAC and VTE in radical cystectomy are sparse and conflicting due to the relatively recent widespread development of NAC for muscle invasive bladder cancer.

Tyson et al. [10] reported results on perioperative complications from NAC prior to radical cystectomy in 122 patients over 6 years. Their findings indicate that the risk of peripheral nerve deficit is significantly increased in patients receiving NAC; however NAC did not affect mortality after 30 days. This study did not find an increased risk of VTE with the use of NAC. Johnson et al. [11] also found no significant increase in the rate of TEEs in patients receiving NAC. In their retrospective study, 78 of $878(8.9 \%)$ patients undergoing radical cystectomy for non-carcinoma in situ bladder cancer received NAC. In the study, $2.6 \%$ of patients receiving NAC and $6.8 \%$ of patients undergoing radical cystectomy alone had a VTE $(p=0.3)$. The most significant limitation within this study is that the NAC group differed significantly from radical cystectomy alone group in terms of patient demographics. Patients that received NAC were significantly younger, more likely to be obese and less likely to be diabetic [11].

Previous studies by Zareba et al. [4] and Duivenvoorden et al. [5] found that patients undergoing NAC are at an increased risk for developing a TEE. The main find- ing of the present study supports the conclusion of these large studies, that platinum-based NAC is an independent predictor for the development of preoperative TEEs in patients undergoing radical cystectomy.

Preoperative VTE risk raises significant considerations for the urologist and medical oncologist in terms of perioperative anticoagulation, preoperative imaging and patient consent. An increased risk of TEEs should be communicated to patients during the preoperative counselling process. The majority of TEEs in the present study were asymptomatic and were diagnosed on routine surveillance imaging. Improved imaging techniques with higher sensitivity may result in increasing diagnoses of non-clinically significant TEEs. Whether or not these subclinical events merit treatment is yet to be elucidated.

Patients diagnosed with a TEE received perioperative therapeutic anticoagulation with LMWH. LMWH is the preferred method of thromboprophylaxis compared to unfractionated heparin as its longer half-life and linear kinetics result in a more predictable response and negate the need for monitoring [12]. Unfractionated heparin is also associated with greater bleeding complications compared to LMWH [13]. The use of perioperative therapeutic anticoagulation in surgical patients raises concerns on increased operative blood loss. Schmitges et al. [14] demonstrated that higher doses of therapeutic LMWH resulted in higher rates of blood transfusion and prolonged drainage duration in patients undergoing open radical retropubic prostatectomy. Furthermore, patients receiving over 80 milligrams of LMWH were 4.1 -fold more likely to require a blood transfusion compared to standard prophylactic doses of LMWH [14]. Interestingly, we found that therapeutic perioperative anticoagulation did not significantly affect operative blood loss and postoperative hemoglobin level. As most VTEs in this study population were asymptomatic and diagnosed on routine preoperative imaging, we have not identified any evidence for routine anticoagulation of patients undergoing NAC.

Risk of VTE is considerably increased in patients with malignancy. The magnitude or fold-increase is difficult to quantify due to variations in patient population, length of follow-up and methodology for detecting VTE [15]. The risk of VTE in patients with malignancy is also increased by the selected treatment modality. One meta-analysis on 8,216 patients demonstrated that platinum-based chemotherapy significantly increased the risk of VTE in patients with advanced solid tumors [3]. The pathogenic mechanism for VTE in these patients is debatable; however, cisplatin induces apoptosis in malignant cells 
with resultant endothelial damage and increased release of endothelial micro particles. Endothelial micro particles drive thrombin production and induce a procoagulable state [16]. In addition, nephrotoxicity is the primary dose-limiting side effect of cisplatin therapy [17]. Renal impairment increases the risk of VTE and this suggests the potential for an alternative pathway mechanism for increased VTEs in this patient population [18].

The present study has limitations and our results should be reviewed with caution. It is a relatively small retrospective study; however, our database was prospectively maintained and no patients were lost to follow-up. Furthermore, a robust number of parameters were recorded and compared in both groups to eliminate the potential for confounders.

\section{Conclusion}

Neoadjuvant cisplatin-based chemotherapy is a significant predictor for perioperative VTE in patients undergoing radical cystectomy. The use of therapeutic anticoagulation in the perioperative period has no significant impact on operative blood loss. Urologists and oncologists should be aware of this important risk and be familiar with perioperative management strategies for TTEs in this patient population. The clinical implications of this issue remain to be fully elucidated. The results of this study do not support routine anticoagulation of patients undergoing NAC. Further prospective randomised trials are required to fully assess the risk of VTE in patients undergoing NAC prior to radical cystectomy and to inform practices relating to perioperative anticoagulation.

\section{References}

1 Advanced Bladder Cancer (ABC) Meta-analysis Collaboration: Neoadjuvant chemotherapy in invasive bladder cancer: update of a systematic review and meta-analysis of individual patient data advanced bladder cancer (ABC) meta-analysis collaboration. Eur Urol 2005;48:202-206.

2 Grossman HB, Natale RB, Tangen CM, Speights VO, Vogelzang NJ, Trump DL, deVere White RW, Sarosdy MF, Wood DP Jr, Raghavan D, Crawford ED: Neoadjuvant chemotherapy plus cystectomy compared with cystectomy alone for locally advanced bladder cancer. N Engl J Med 2003;349:859-866.

3 Seng S, Liu Z, Chiu SK, Proverbs-Singh T, Sonpavde G, Choueiri TK, Tsao CK, Yu M, Hahn NM, Oh WK, Galsky MD: Risk of venous thromboembolism in patients with cancer treated with Cisplatin: a systematic review and meta-analysis. J Clin Oncol 2012; 30:4416-4426.

4 Zareba P, Patterson L, Pandya R, Margel D, Hotte SJ, Mukherjee SD, Elavathil L, Daya D, Shayegan B, Pinthus JH: Thromboembolic events in patients with urothelial carcinoma undergoing neoadjuvant chemotherapy and radical cystectomy. Urol Oncol 2014;32: 975-980.

5 Duivenvoorden WC, Daneshmand S, Canter D, Lotan Y, Black PC, Abdi H, van Rhijn BW, Fransen van de Putte EE, Zareba P, Koskinen I, Kassouf W, Traboulsi SL, Kukreja JE, Boström PJ, Shayegan B, Pinthus JH: Incidence, characteristics and implications of thromboembolic events in patients with muscle invasive urothelial carcinoma of the bladder undergoing neoadjuvant chemotherapy. J Urol 2016;196:1627-1633.
6 Doiron RC, Booth CM, Wei X, Siemens DR: Risk factors and timing of venous thromboembolism after radical cystectomy in routine clinical practice: a population-based study. BJU Int 2016;118:714-722.

7 Murray KM, Parker W, Stephany H, Redger K, Mirza M, Lopez-Corona E, Holzbeierlein JM, Lee EK: Venous thromboembolism after radical cystectomy: Experience with screening ultrasonography. Arab J Urol 2016;14: $37-43$.

8 Sun AJ, Djaladat H, Schuckman A, Miranda G, Cai J, Daneshmand S: Venous thromboembolism following radical cystectomy: significant predictors, comparison of different anticoagulants and timing of events. J Urol 2015;193:565-569.

9 VanDlac AA, Cowan NG, Chen Y, Anderson RE, Conlin MJ, La Rochelle JC, Amling CL, Koppie TM: Timing, incidence and risk factors for venous thromboembolism in patients undergoing radical cystectomy for malignancy: a case for extended duration pharmacological prophylaxis. J Urol 2014;191:943947.

10 Tyson MD 2nd, Bryce AH, Ho TH, Carballido EM, Castle EP: Perioperative complications after neoadjuvant chemotherapy and radical cystectomy for bladder cancer. Can $\mathbf{J}$ Urol 2014;21:7259-7265.

11 Johnson DC, Nielsen ME, Matthews J, Woods ME, Wallen EM, Pruthi RS, Milowsky MI, Smith AB: Neoadjuvant chemotherapy for bladder cancer does not increase risk of perioperative morbidity. BJU Int 2014;114:221-228.
12 Green B, Greenwood M, Saltissi D, Westhuyzen J, Kluver L, Rowell J, Atherton J: Dosing strategy for enoxaparin in patients with renal impairment presenting with acute coronary syndromes. Br J Clin Pharmacol 2005;59:281-290.

13 Cossette B, Pelletier ME, Carrier N, Turgeon M, Leclair C, Charron P, Echenberg D, Fayad T, Farand P: Evaluation of bleeding risk in patients exposed to therapeutic unfractionated or low-molecular-weight heparin: a cohort study in the context of a quality improvement initiative. Ann Pharmacother 2010;44:994-1002.

14 Schmitges J, Trinh QD, Jonas L, Budäus L, Larbig R, Schlomm T, Karakiewicz PI, Heinzer H, Huland H, Graefen M, Steuber $\mathrm{T}$ : Influence of low-molecular-weight heparin dosage on red blood cell transfusion, lymphocele rate and drainage duration after open radical prostatectomy. Eur J Surg Oncol 2012;38:1082-1088.

15 Khorana AA, Connolly GC: Assessing risk of venous thromboembolism in the patient with cancer. J Clin Oncol 2009;27:4839-4847.

16 Lechner D, Kollars M, Gleiss A, Kyrle PA, Weltermann A: Chemotherapy-induced thrombin generation via procoagulant endothelial microparticles is independent of tissue factor activity. J Thromb Haemost 2007;5: 2445-2452.

17 Miller RP, Tadagavadi RK, Ramesh G, Reeves WB: Mechanisms of Cisplatin nephrotoxicity. Toxins (Basel) 2010;2:2490-2518.

18 Wattanakit K, Cushman M, Stehman-Breen C, Heckbert SR, Folsom AR: Chronic kidney disease increases risk for venous thromboembolism. J Am Soc Nephrol 2008;19:135-140. 